\title{
Assessment of Aqueous Extract of Humulus Lupulus Effects on Seizure Induced by Intraperitoneal Injection of Pentylenetetrazole in Mice
}

\author{
Simin Namvar Aghdash*, Soheila Nasirifard \\ Department of Biology, Faculty of Basic Sciences, Azarbaijan Shahid Madani University, Tabriz, Iran
}

\section{ABSTRACT}

Introduction: Epilepsy is one of the most common disorders of the brain, affecting at least 50 million persons worldwide. Despite a variety of current antiepileptic drugs, research for discovering new drugs with more efficacies and less side effects has been continued. Herbal medicine has various natural substances and proper context for this type of research. The aim of this study was to investigate the effect of Humulus lupulus (Hops) extract on seizure attacks in an experimental animal model. Materials and Methods: 40 male mice have been chosen randomly and divided into 5 groups; including control group, sham group, and three experimental groups. Treated mice received aqueous extract of Humulus lupulus via gavage at doses of 200, 400, and $600 \mathrm{mg} / \mathrm{kg}$ for 4 weeks. Thirty minutes after gavage with different doses of the herb or distilled water (sham mice), pentylenetetrazole (PTZ; 45mg/kg) was injected intraperitoneally. Animals immediately transferred to a special cage and the seizure behaviors were recorded by a camera during a 25 minutes period. Results: Data analysis indicated that the aqueous extract of Humulus lupulus had a significant inhibitory effect on PTZ-induced seizure. Treatment with Humulus lupulus significantly increased the latency of seizure onset, decreased the intensity of seizure, and seizure duration. Conclusion: The attained results showed that Hops extract has anticonvulsant effect on PTZ-induced seizure and may be useful for treatment of epilepsy.

\section{Key words:}

1. Seizures

2. Epilepsy

3. Pentylenetetrazole

* Corresponding Author: Simin Namvar Aghdash

E-mail: Siminnamvar2@gmail.com 


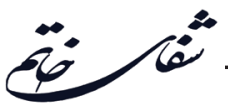

\section{ارزيابى اثرات عصاره آبى گياه رازك بر تشنجهاى ناشى از تزريق داخل صفاقى ينتيلن تترازول در موش هاى سورى}

$$
\text { سيمين نامور آغداش"، سهيلا نصيرىفرد }
$$

كروه زيست شناسى، دانشكده علوم پايه، دانشعاه شهيد مدنى آذربايجان، تبريز، ايران

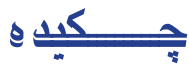

مقدمه: صرع يكى از شايعترين اختلالات مغزى است كه حداقل • ه ميليون نفر از جمعيت جهان را تحت

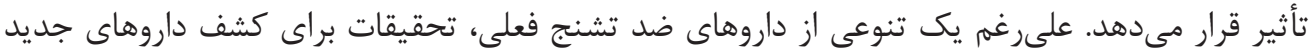

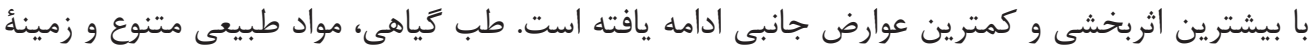

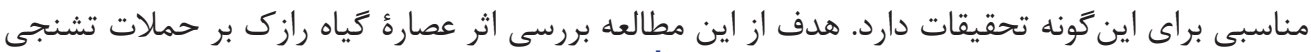

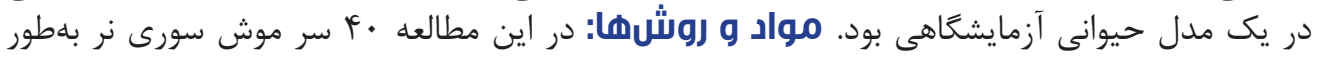

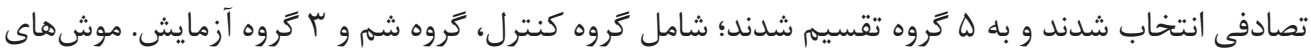

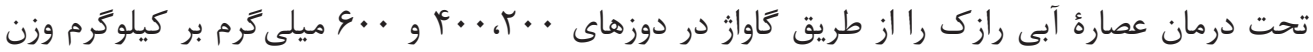

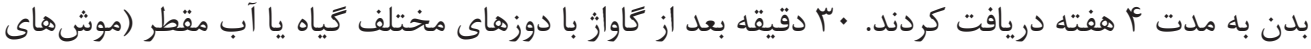

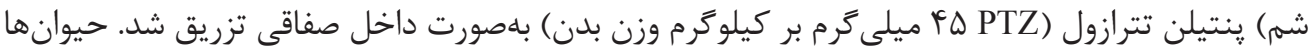

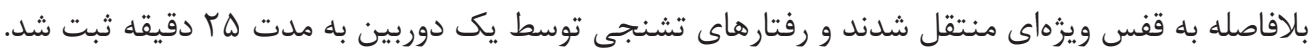

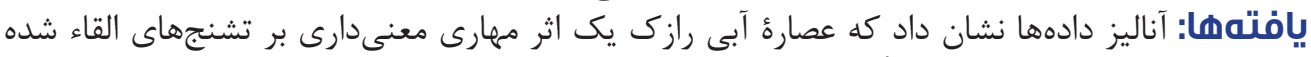

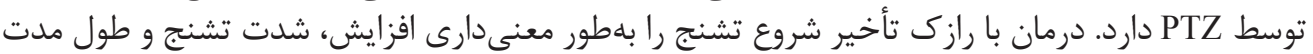

كليد وازهها:

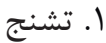
T r.

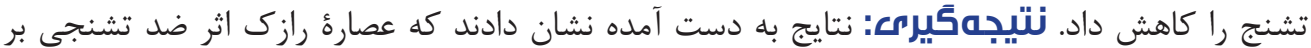

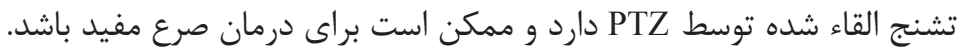

$$
\text { * نويسنده مسئول: سيمين نامور آغداش }
$$


استفاده مىشود (1) (1)؛ از اين روبه نظر مىرسد كه اين كياه

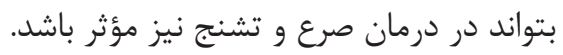

مواد و روشها - - ماد

$$
\text { حيوانات و شرايط آزمايش }
$$

اين مطالعُ تجربى در دانشگاه شهيد مدنى آذربايجان بر روى

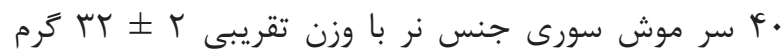

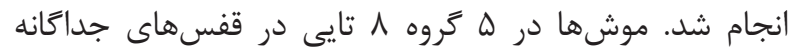

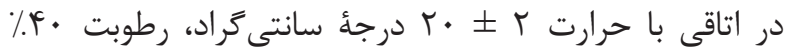

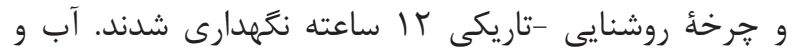

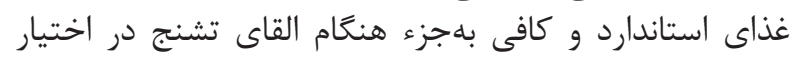

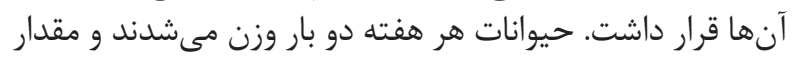

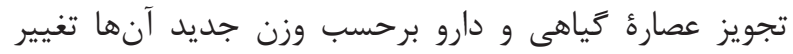

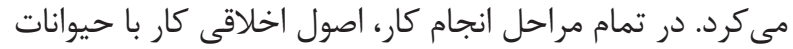

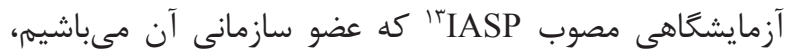
رعايت شده است.

$$
\text { تهيئ عصارهُ آبى تياه رازى }
$$

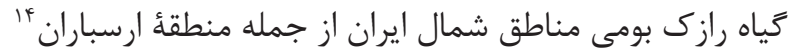

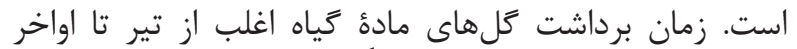

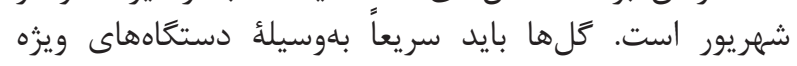

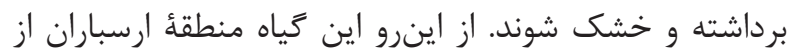

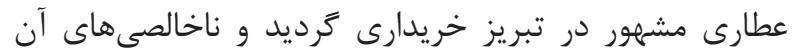

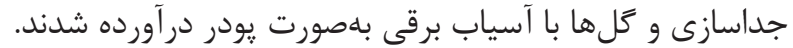

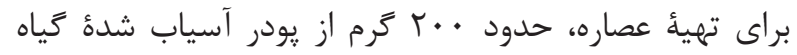

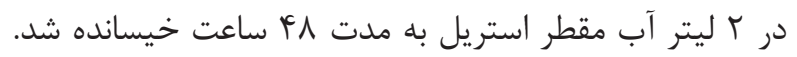

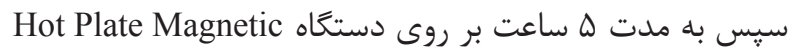

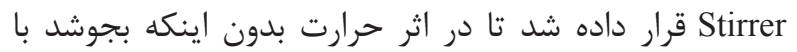

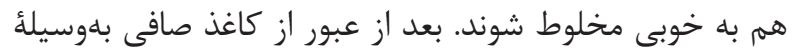

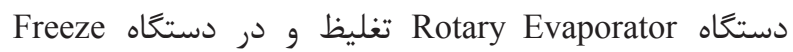

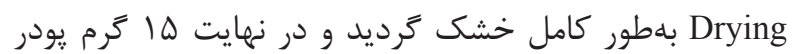

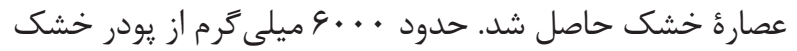

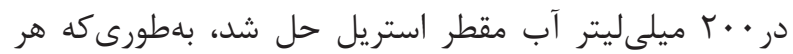

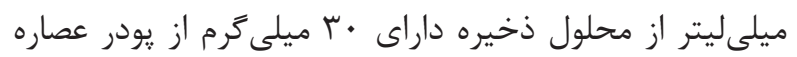

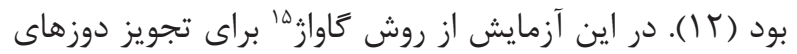

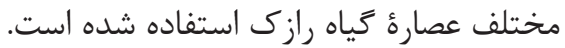

\section{ايجباد تشنج}

مدل مطالعاتى صرع در اين تحقيق، كيندلينَ شيميايى با دران

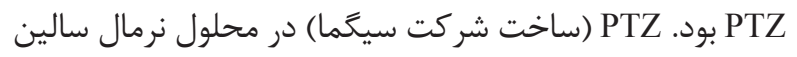

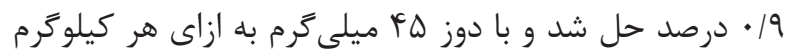

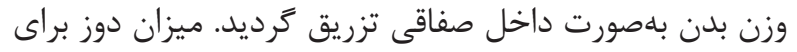

${ }^{1}$ Epilepsy

${ }^{2}$ Kindling

${ }^{3}$ Epileptogenesis

${ }^{4}$ Pentylenetetrazole

${ }^{5}$ World Health Organization

${ }^{6}$ Humulus lupulus

${ }^{7}$ Cannabaceae

${ }^{8}$ Cones

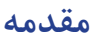

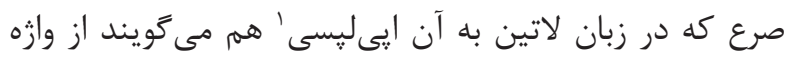

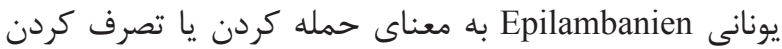

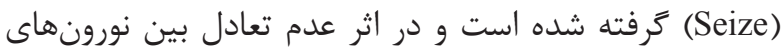

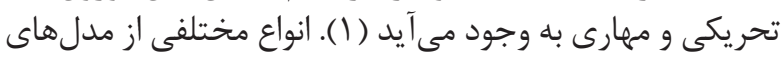

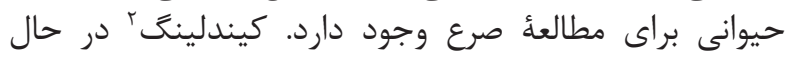

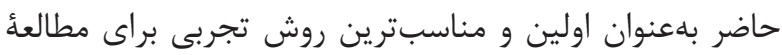

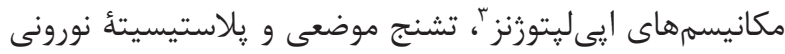

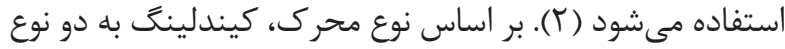

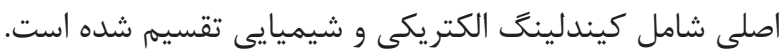

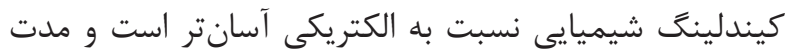

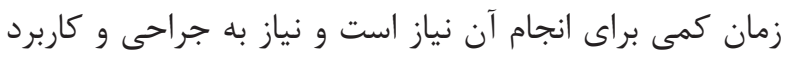

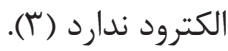

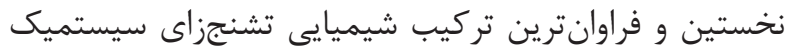

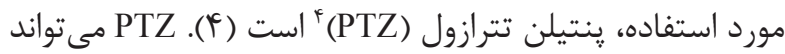

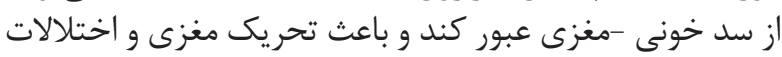

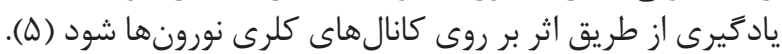

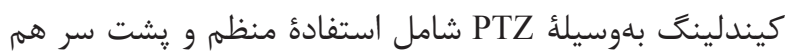

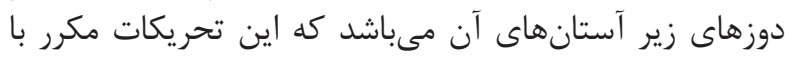

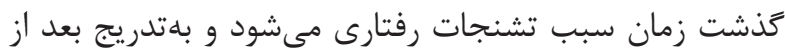

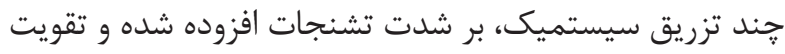

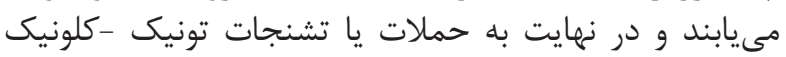

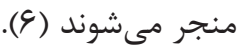

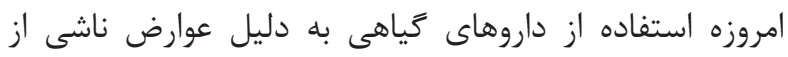

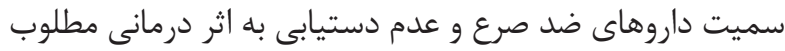

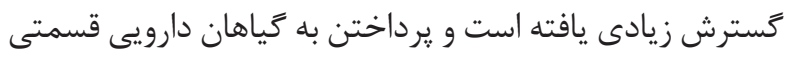

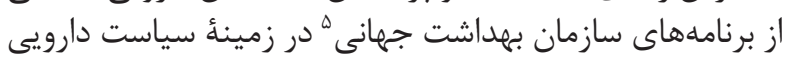

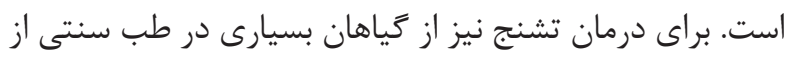
كذشتهُ دور تاكنون استفاده شده است (V-9).

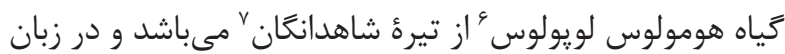

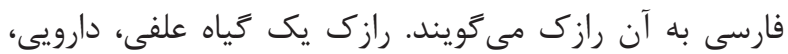

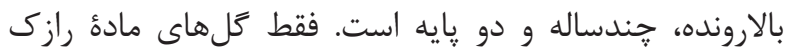

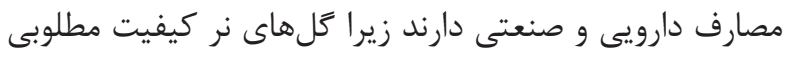

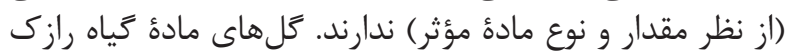

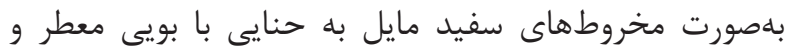

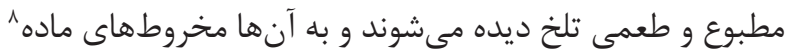

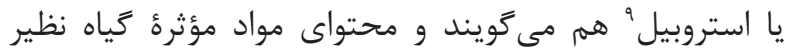

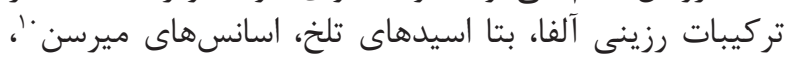

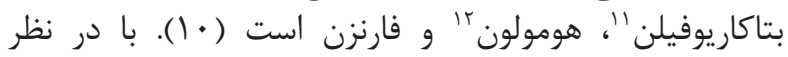

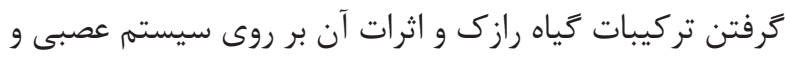

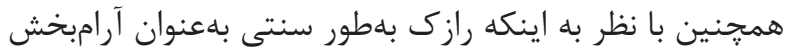

\footnotetext{
${ }^{9}$ Strobile

${ }^{10}$ Myrcene

${ }^{11}$ Beta-Caryophyllene

${ }^{12}$ Humulone

${ }^{13}$ International Association for the Study of Pain

${ }^{14}$ Arasbaran

${ }^{15}$ Gavage
} 


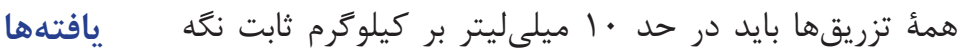

اثر دوزهاى مختلف رازك بر يِيشرفت مراحل تشنج

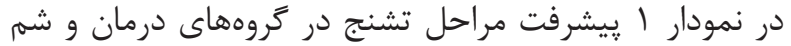

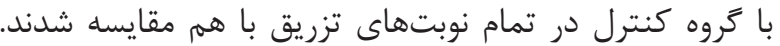

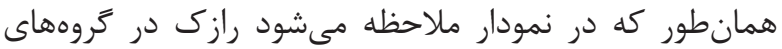

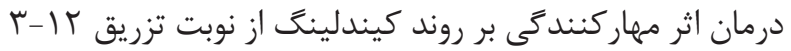

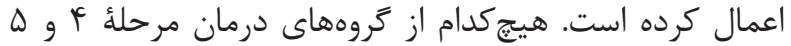

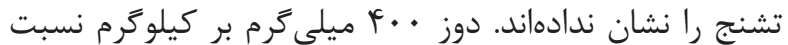

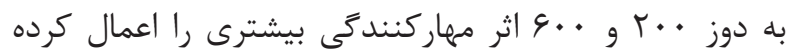

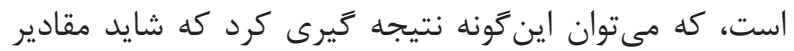

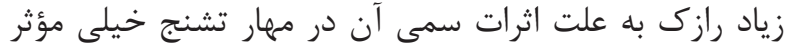

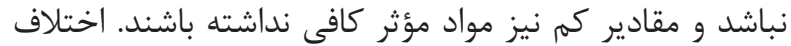

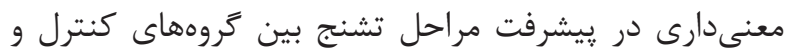

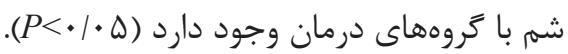

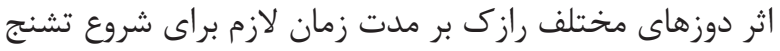

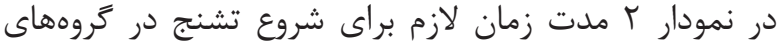

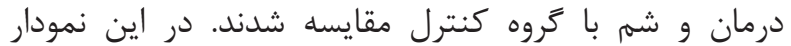

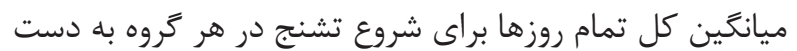

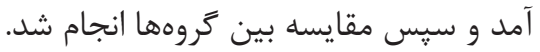

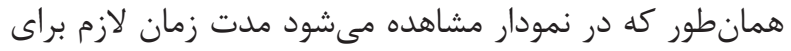

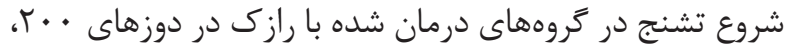

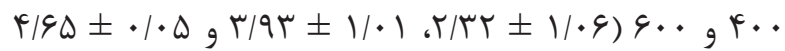

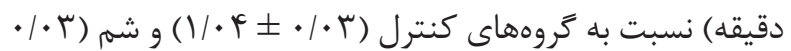

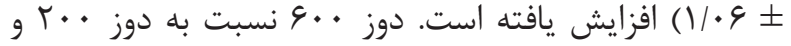

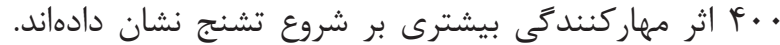

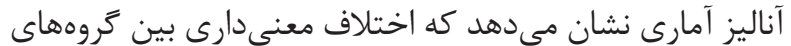

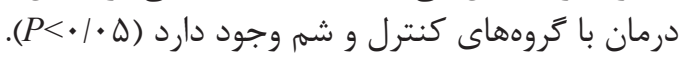

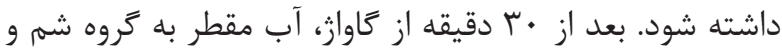

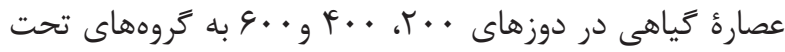

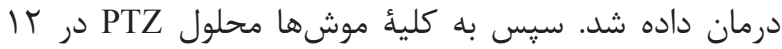

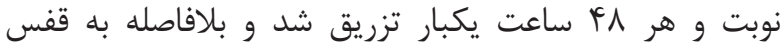

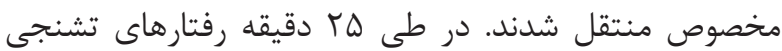

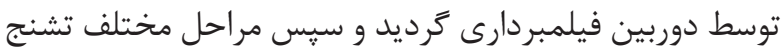

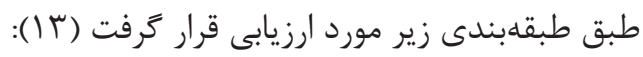

$$
\text { • مر حلة صفر: عدم ياسخ لئح }
$$

• مر حلة ا: حركات و انقباضات عضلات صورت، دهان و كوشها

$$
\text { • مرحله r: موجهاى انقباضى بدن }
$$

• مرحله بّ: انقباض ميو كلونيك بدن و ايستادن روى دو يا لتراي • مرحله f: كلونوس اندام جلويى و افتادن حيوان به يهلو • مرحله ه: از دست دادن تعادل و افتادن به يشت و تشنجهاى

$$
\text { • مرحله \&: مركى كلونيك زيوان اليزه }
$$

همجنين مدت زمان لازم براى شروع تشنج (نشان دادن مرحلة

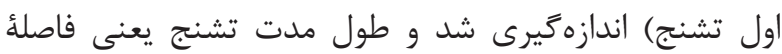

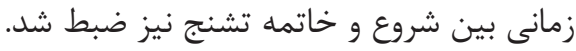

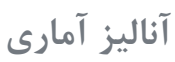

در اين مطالعه نتايج بلهدستآمده بهصورت ميانكين \pm انحراف آنداف

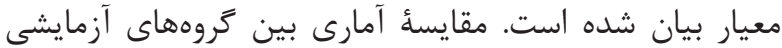

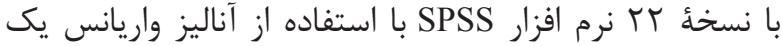

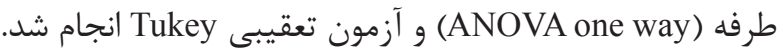
اختلاف كمتر از ه ••>P معنى

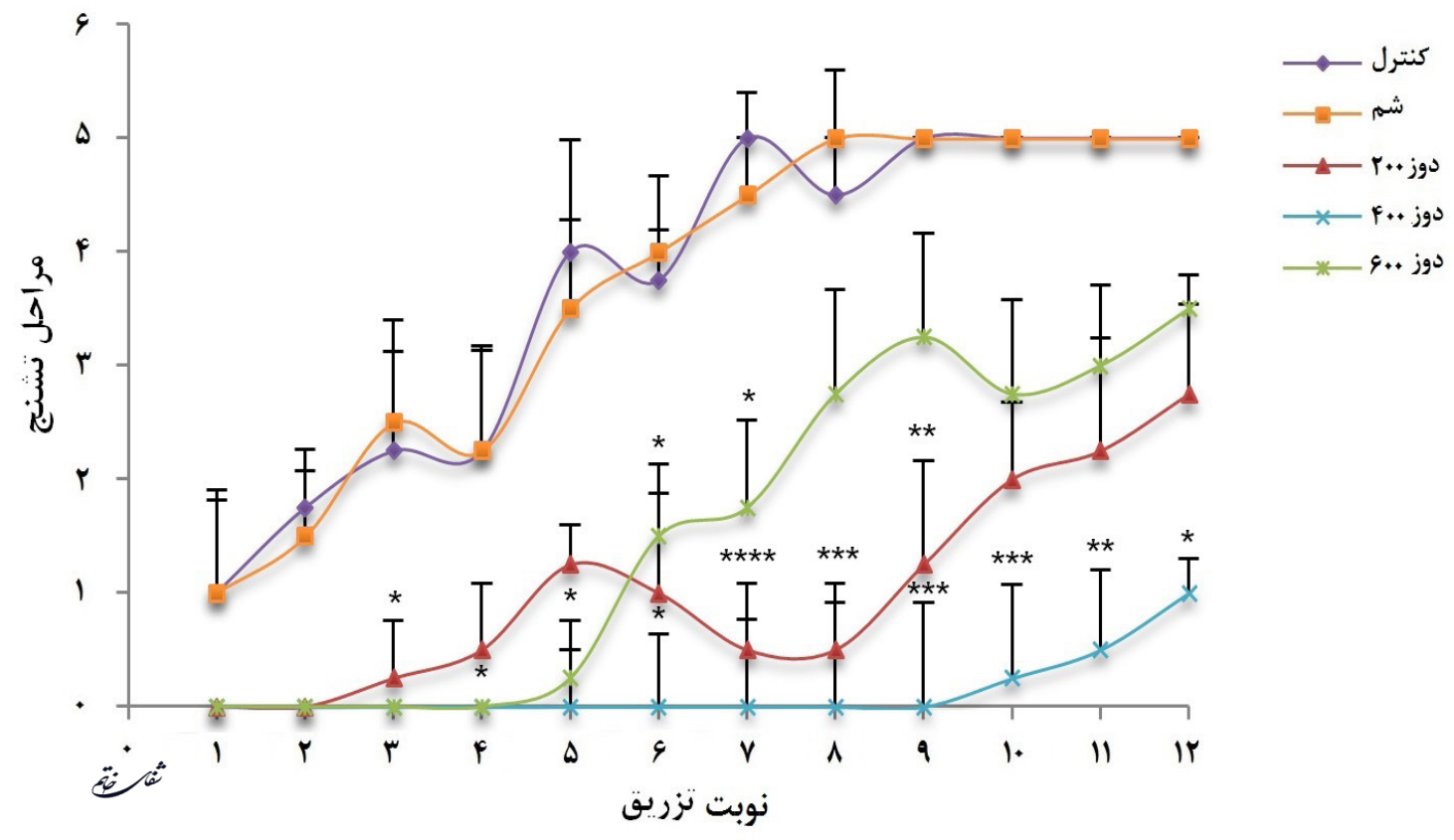

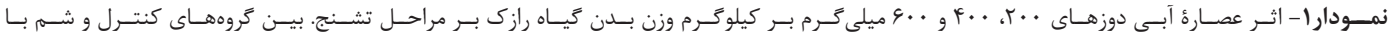

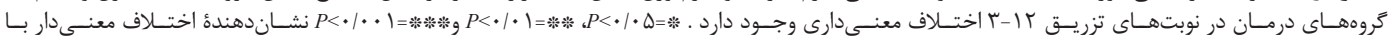

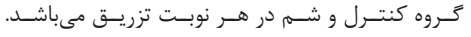




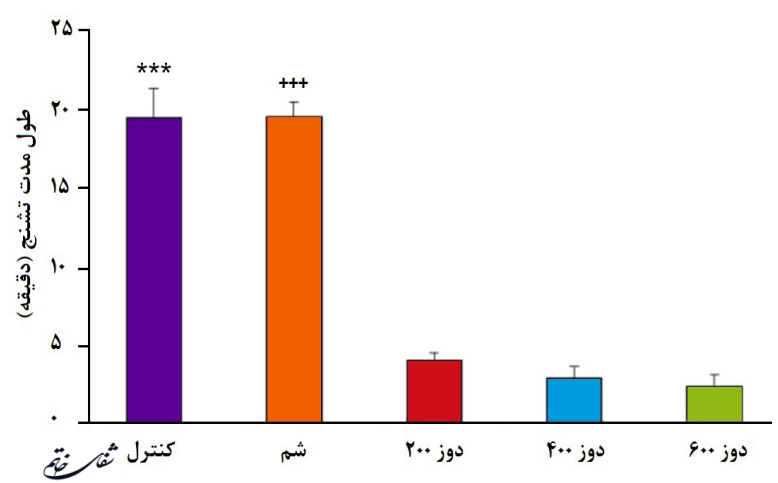

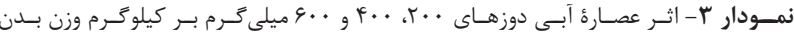

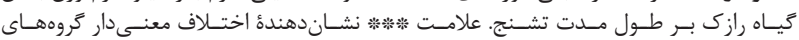

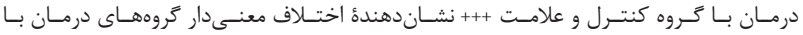

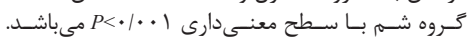

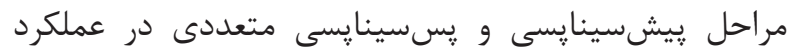

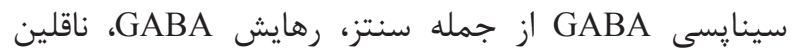

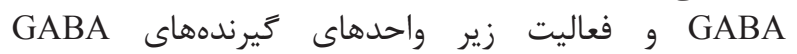

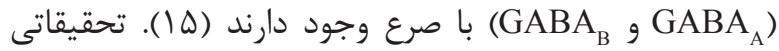

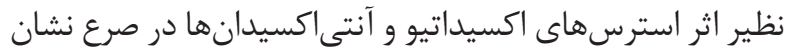

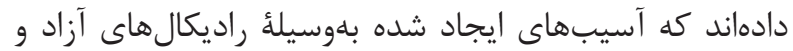

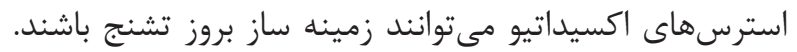

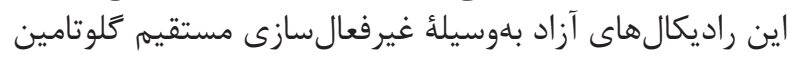

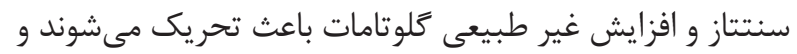

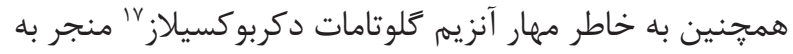

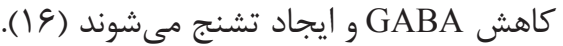

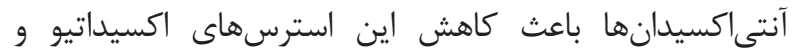

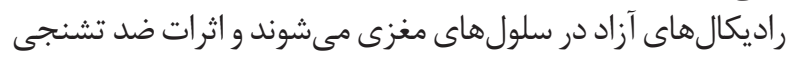

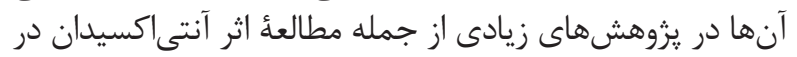

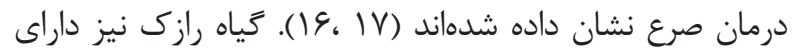

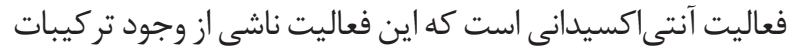

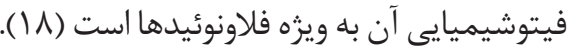

كزارش شده است كه فلاونوئيدها يك گروه از تركيبات يلىفنيك

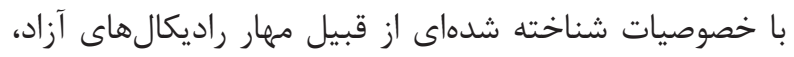

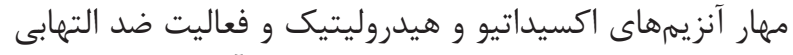

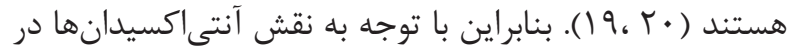

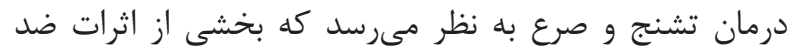

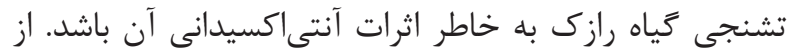

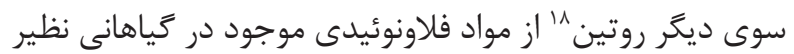

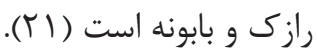

بررسى اثرات ضد تشنجى تجويز روتين به داخل بطن مغز

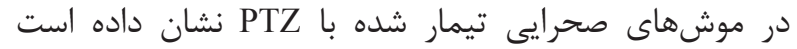

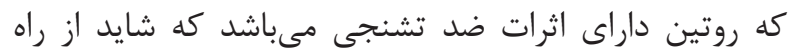

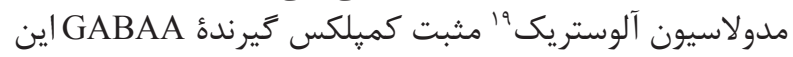

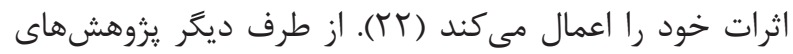

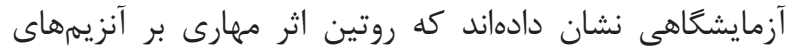

${ }^{16}$ gamma-Aminobutyric acid

${ }^{17}$ Glutamate decarboxylase

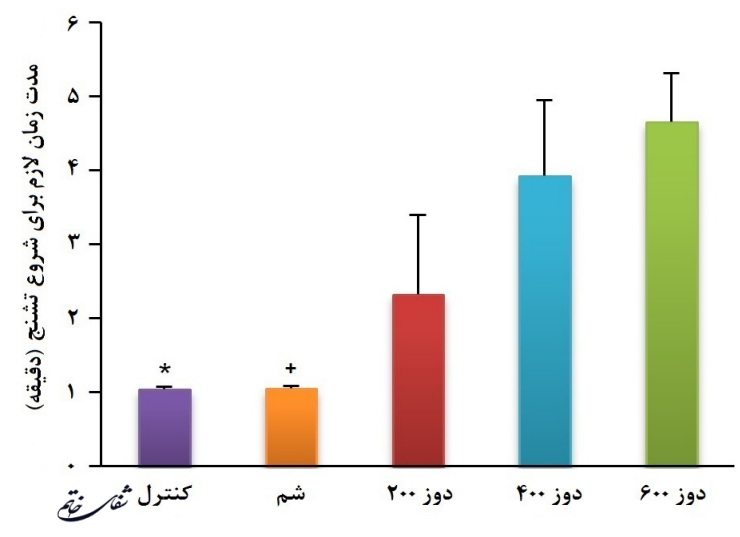

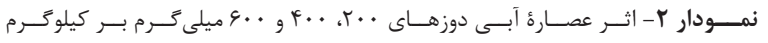

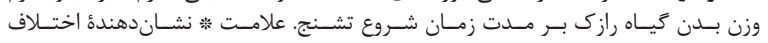

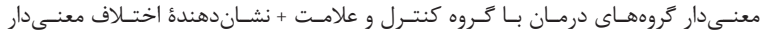

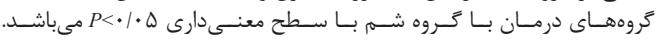

اثر دوزهاى مختلف رازك بر طول مدت تشنج همانطور كه در نمودار r نشان داده شده است، رازى به بهور

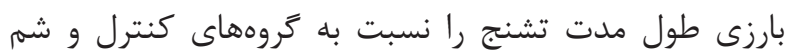

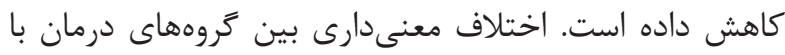

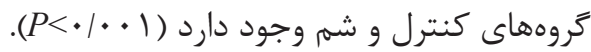

\section{بحث و نتيجه كَيرى}

نتايج آزمايش ما نشان مى تهدد كه دوزهاى مورد استفاده در

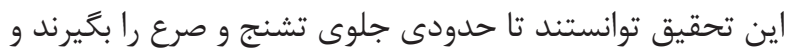

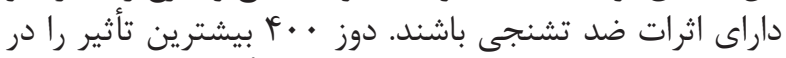

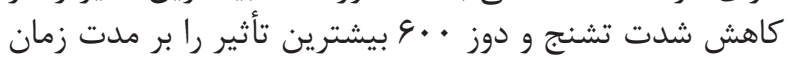

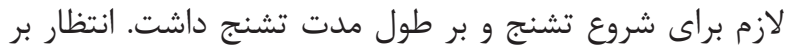

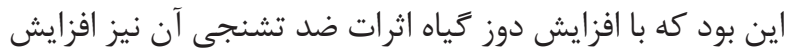

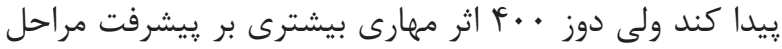

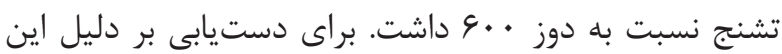

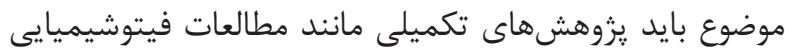

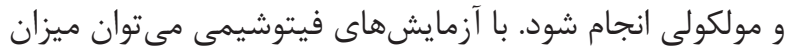

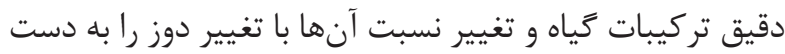

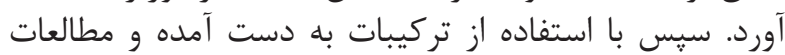

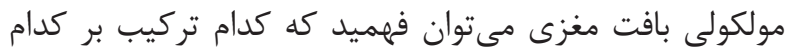
مكانيسم مؤثر در ايجاد صرع تأثير بيشترى داشئ داشته است.

در مورد اثر گياه رازك در درمان تشنج و صرع، در مرحلة اول

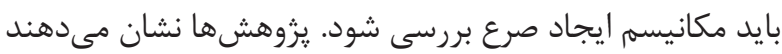

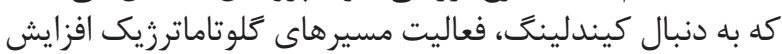

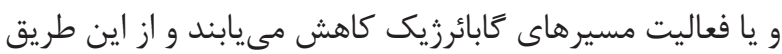

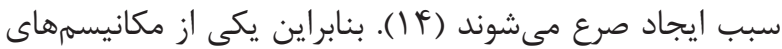

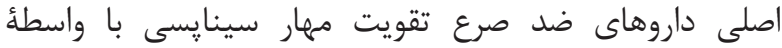

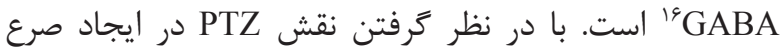

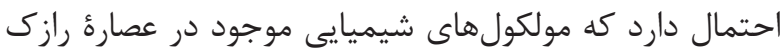

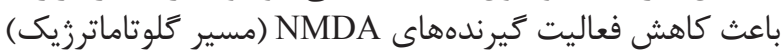

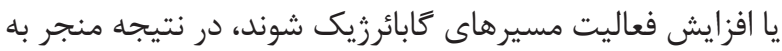
تضعيف تشنجات صرعى ناشى از PTZ گردند.

\footnotetext{
${ }^{18}$ Rutin

${ }^{19}$ Allosteric
} 
مغز موشهاى صحرايى بلهوسيلة مهار اين آنزيهم افزايش مى آندهد

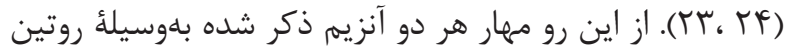

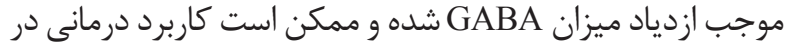
اختلالات نورولوزيكى از جمله تشنج و صرع داشته باشد.

1. Magiorkinis E, Sidiropoulou K, Diamantis A. Hallmarks in the history of epilepsy: epilepsy in antiquity. Epilepsy Behav. 2010; 17(1):103-8 .

2. McNamara JO, Byrne MC, Dasheiff RM, Fitz JG. The kindling model of epilepsy: a review. Prog Neurobiol. 1980; 15(2): 139-59.

3. Louis ED, Williamson PD, Darcey T. Experimental models of chronic focal epilepsy: a critical review of four models. Yale J Biol Med. 1987; 60(3): 255-72.

4. De Deyn PP, D’Hooge R, Marescau B, Pei YQ. Chemical models of epilepsy with some reference to their applicability in the development of anticonvulsants. Epilepsy Res. 1992; 12(2): 87-110.

5. MacDonald RL, Barker JL. Pentylenetetrazol and penicillin are selective antagonists of GABA-mediated post-synaptic inhibition in cultured mammalian neurones. Nature. 1977; 267: 720-1.

6. De Sarro, Palme E, Costa N, Marra R, Gratteri S, De Sarro A, et al. Effects of compounds acting on GABA $\mathrm{B}$ receptors in the pentylenetetrazole kindling model of epilepsy in mice. Neuropharmacol. 2000; 39(11): 2147-61.

7. Kim HJ, Jee EH, Ahn KS, Choi HS, Jang YP. Identification of marker compounds in herbal drugs on TLC with DART-MS. Arch Pharm Res. 2010; 33(9): 1355-9.

8. Reyes-García V. The relevance of traditional knowledge systems for ethnopharmacological research: theoretical and methodological contributions. J Ethnobiol Ethnomed. 2010; 6: 32-6.

9. Moussally K, Oraichi D, Bérard A. Herbal products use during pregnancy: prevalence and predictors. Pharmacoepidemiol Drug Saf. 2009; 18(6): 454-61.

10. Shishehgar R, Monadi A. Study of sedation and preanesthetic effects of polar, semi-polar and non-polar fractions of hop (Humulus lupulus L.) extract compared with diazepam in rats. Middle East J Sci Res. 2013; 16(6): $762-8$.

11. Franco L, Sánchez C, Bravo R, Rodriguez A, Barriga C, Juánez JC. The sedative effects of hops (Humulus lupulus), a component of beer, on the activity/rest rhythm. Acta Physiol Hunga. 2012; 99(2): 133-39.

12. Rezvani ME, Roohbakhsh A, Mosaddegh MH, Esmailidehaj M, Khaloobagheri F, Esmaieli H. Anticonvulsant and depressant effects of aqueous
GABA

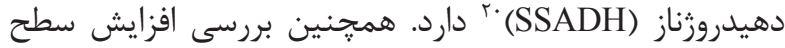

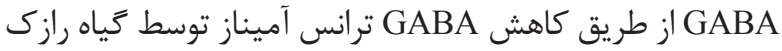

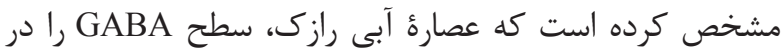

منابع

extract of Carum copticum seeds in male rats. Epilepsy Behav. 2011; 22(2): 220-5.

13. Palizvan MR, Ghaznavi-Rad E. Naloxan enhanced inhibitory effect of verapamil on seizure induced by pentylenetetrazol in male rats. Res Pharm Sci. 2014; 9(4): 295-9.

14. Gelfuso EA, Liberato JL, Cunha AO, Mortari MR, Beleboni RO, Lopes NP. Parawixin2, a novel nonselective GABA uptake inhibitor from Parawixia bistriata spider venom, inhibits pentylenetetrazole-induced chemical kindling in rats. Neurosci Lett. 2013; 543: 12-6.

15. Olsen RW, Avoli M. GABA and epileptogenesis. Epilepsia. 1997; 38(4): 399-407.

16. Sudha K, Rao AV, Rao A. Oxidative stress and antioxidants in epilepsy. Clin Chim Acta. 2001; 303(1-2); 19-24.

17. Nemade ST, Melinkeri RR. Oxidative and antioxidative status in epilepsy. Paravara Med Rev. 2010; 2(4): 8-10.

18. Krofta K, Mikyška A, Hašková D. Antioxidant characteristics of hops and hop products. J Inst Brew. 2008; 114(2): 160-6.

19. Kowalczyk D, Świeca M, Cichocka J, Gawlikziki U. The phenolic content and antioxidant activity of the aqueous and hydroalcoholic extracts of hops and their pellets. J Inst Brew. 2013; 119(3): 103-10.

20. Singh LR, Singh OM. Datura stramonium: An overview of its phytochemistry and pharmacognosy. J Pharmacogn Phytochem. 2013; 5(3): 143-8.

21. ShahBN,PanchalAM,ModiD.Phyto-parmacological profile of Humulus Lupulus. Pharmacologyonline. 2010; 1: 719-36.

22. Nassiri-Asl M, Shariati-Rad S, Zamansoltani F. Anticonvulsive effects of intracerebroventricular administration of rutin in rats. Prog Neuropsychopharmacol Biol Psychiatry. 2008; 32(4): 989-93.

23. Weeks SB. Formulations of dietary supplements and herbal extracts for relaxation and anxiolytic action. Med Sci Monit. 2009; 15(11): RA256-62.

24. TaoYH, Jiang DY, Xu HB, Yang X1. Inhibitory effect of Erigeron breviscapus extract and its flavonoid components on GABA shunt enzymes. Phytomedicine. 2008; 15(1-2): 92-7.

\footnotetext{
${ }^{20}$ Succinic semialdehyde dehydrogenase
} 